\title{
RESPONSABILIDADE SOCIAL OU ALIENAÇÃO?
}

\author{
Aline Dionízio Leal ${ }^{1}$ \\ Melânia Mendonça Rodrigues ${ }^{2}$
}

\begin{abstract}
RESUMO
O presente artigo tem como objetivo analisar a inserção da lógica empresarial na educação, mais precisamente, o conceito de responsabilidade social, entendida como o impulso à ação coletiva do empresariado, tendo em vista o alcance de objetivos político-ideológicos (MARTINS, 2009). Para fundamentar a pesquisa, fizeram-se necessários estudos bibliográficos baseados em autores como MARTINS (2009), SILVA e RODRIGUES (2013), VITULLO (2012), como também, buscas em sítios da internet sobre a temática. O texto aborda as ações desenvolvidas pelo empresariado, visando à conformação dos trabalhadores, do século XIX - com as vilas operárias - ao mandato petista do expresidente Lula, quando a classe empresarial entendeu que a educação era o meio mais seguro e eficaz de moldar as futuras gerações, adequando-as à lógica do mercado (MARTINS, 2013). Observou-se a evolução do conceito acima citado, passando do "valor agregado" ao "responsabilidade social", que engloba outros clichês de "solidariedade", "sustentabilidade", "gestão responsável", adotados por tantas empresas e incentivados pelo governo em suas mais variadas instâncias, a fim de angariar tanto capital financeiro quanto apoio midiático, tornando as empresas melhor aceitas pela população.

Palavras-chave: Educação; Responsabilidade social; Empresários e educação.
\end{abstract}

\section{SOCIAL RESPONSIBILITY OR ALIENATION?}

\section{ABSTRACT}

The present article has as objective to analyze the insertion of management logic in education, most specifically, the concept of social responsability, understood as impulse to collective action of entrepreneurs, considering the range of political and ideological objectives (MARTINS, 2009). To base the research, it was necessary to do bibliographical studies based in authors as MARTINS (2009), SILVA and RODRIGUES (2013), VITULLO (2012), as well as researches in online sites about the theme. The text abords the developed actions for entrepreneurs, directing to resignation of workers, of XIX century - with the workers villas - until the mandate of ex-president Lula, when the entrepreneur class understood that education was the most safe and efficient way to mould the future generations, adapt them to market logic (MARTINS, 2013). It was observed the evolution of social responsability concept, changing of "increased value" to "social responsability", which involves anothers clichés as "solidarity", "sustainability", “ responsable management", adoptes for many companies and incites by government in their multiple instances, to recruit financial and media capital, becoming the companies better accepted by population.

Keywords: Education; Social Responsability; Entrepreneurs and education. 


\section{INTRODUÇÃO}

O presente artigo tem como objetivo analisar a inserção da lógica empresarial na educação, mais precisamente, o conceito de responsabilidade social que visa "impulsionar a classe empresarial para a ação coletiva na busca de determinados objetivos políticos e ideológicos" (MARTINS, 2009, p. 151), por meio da educação. Isto porque se identificou um aumento da participação do setor privado em questões pertencentes ao campo social, assim sendo, quanto maior o interesse e a amplitude dessa participação, mais importante é tomar conhecimento da intensidade e do alcance dessas ações privadas.

O interesse em estudar a imersão da lógica empresarial na busca da consolidação de uma nova sociabilidade, bem como a atuação das empresas no lugar do Estado, investindo na questão de cunho social, motivou a realização da pesquisa "Vista a camisa cidadã: responsabilidade social ou alienação?" que busca estudar o caso do programa "caravana do bem" desenvolvido por uma empresa de callcenter na cidade de Campina Grande ${ }^{3}$.

Para fundamentar a pesquisa, fizeram-se necessários estudos bibliográficos baseados em autores como MARTINS (2009), SILVA e RODRIGUES (2013), VITULLO (2012), como também, buscas em sítios da internet sobre a temática. Procedeu-se, ainda, a uma revisão histórica das ações desenvolvidas pelo empresariado, visando à conformação dos trabalhadores, desde o século XIX, com as vilas operárias, até iniciativas mais concretas, como as que foram realizadas no governo de Fernando Henrique Cardoso, consolidadas no mandato petista com o ex-presidente Lula, o que contribui para compreendermos melhor os fenômenos individuais e os processos organizacionais e políticos da sociedade.

Os estudos desenvolvidos permitiram observar-se a evolução do conceito, que passou de "valor agregado", "acenado como sendo a preocupação das empresas com projetos sociais e com normas de bom convívio quotidianas" (VITULLO, 2012, p. 30), ao que conhecemos hoje como responsabilidade social, englobando outros clichês de "sustentabilidade", "gestão responsável", dentre outros, que são adotados por tantas empresas e incentivados pelo governo em suas mais variadas instâncias, a fim de angariar tanto capital financeiro quanto apoio midiático, já que estudos vêm comprovando que tais empresas são popularmente melhor aceitas.

Percebe-se, pois, que o empresariado entendeu que a educação era o meio mais seguro e eficaz de moldar as futuras gerações, adequando-os à lógica do mercado de trabalho, de uma maneira que se tornou tão "natural", que tais iniciativas são louvadas por muitos. Mais do que velhos "clichês", conceitos clássicos são fetichizados, difundidos no senso comum e entendidos de maneira equivocada ou, mesmo, sendo compreendidos com uma conotação diferente de sua origem, "[podendo-se] destacar dentre outras, as categorias de "cidadania", "solidariedade", "democracia" e "sociedade civil"." (VITULLO, 2012, p.168).

Tais termos agregam força às ações sociais, na medida em que é deturpada, por exemplo, a noção de solidariedade, que hoje é entendida como dever caritativo para com a sociedade. Ou a de democracia, reduzida à mera participação eleitoral, em lugar do aumento da participação popular nas decisões políticas.

O termo cidadão que, desde a Revolução Francesa, carrega consigo uma configuração de sentido que expressa uma carga de transformações de uma nova era 
abrange "quem se dizia cidadão $o^{4}$ faria parte, aceitaria e compartilharia dos novos ideais revolucionários. Se identificaria, em suma, com novos tempos." (VITULLO, 2012, p. 13).

Esses exemplos de como as palavras ganham força e são capazes de difundir valores se inculcadas de maneira "correta" 5 , do mesmo modo que outros termos, como "cidadania e solidariedade" são demandas dos governos dos anos de 1990, os quais eram conduzidos, pelo modelo econômico vigente, a adotar parceiras público/privado, desobrigando-se de investir em políticas sociais (PAOLI, 2002).

\section{RESPONSABILIADE SOCIAL E A CONSOLIDAÇÃO DE UMA NOVA SOCIABILIDADE EMPRESARIAL.}

A preocupação empresarial em moldar um novo tipo de consciência na classe trabalhadora partiu desde o século XIX com as vilas operárias, sendo que estas possuíam um caráter disciplinador, ao passo que reuniam "os trabalhadores e suas famílias em um espaço urbano controlado por um código disciplinar e espacial rigidamente estabelecido" (MARTINS, 2013. Pag. 75) e transmitindo aos trabalhadores bem como a seus filhos através da escolha de um padrão de sociabilidade novo que os subordinava as exigências do trabalho na fábrica.

Naquele contexto, investir na educação escolar, mais do que uma atitude puritana de cuidado com as futuras gerações, se constituía numa importante estratégia de "determinar os comportamentos racionais: o emoldamento das consciências infantis a submissão do domínio clérigocapitalista”. (RAGO, 1985, p.184 apud MARTINS, 2013, p.75).

Tal iniciativa já demonstrava a preocupação empresarial com o que pensava a classe trabalhadora. A partir do início do século XX, com atuação mais incisivamente nos anos de 1990, inicialmente com o governo de Collor de Melo, e com a "unificação da classe empresarial em torno do projeto neoliberal" (MARTINS, 2013, p. 75), buscava-se uma mobilização popular em defesa do mercado, levando consigo os princípios da competitividade e da produtividade.

Assim, dos anos de 1990 até os dias atuais, o Brasil vive uma ampla expansão no número de organizações não governamentais, apresentadas como única alternativa à ineficiência e ineficácia do Estado, como também, ao utilitarismo do mercado, razão por que se autodenominam de "Terceiro Setor".

Apesar desse avanço na década de 1990, tal "onda" de organizações em prol do "bem comum" já encontrara espaço para expansão desde os 1970, com a crise capitalista, cuja superação implicava a retomada do ciclo de acumulação. A solução, então encontrada, foi aperfeiçoar o limite do processo produtivo e transformar serviços que antes eram de responsabilidade do Estado em fonte de lucro, em mercadoria, traço que, diga-se de passagem, é marcante na nova etapa neoliberal (VITULLO, 2012), reduzindo o papel do Estado como garantidor e provedor de serviços e políticas públicas.

Entram em voga chavões como "cada um faz sua parte", seja atuando como voluntário, participando de alguma organização, instituto ou fundação sem fins lucrativos. Neste sentido, define-se o "terceiro setor" segundo o sítio do BNDES, como se constituindo,

Na esfera de atuação pública não-estatal, formado a partir de iniciativas privadas, voluntárias, sem fins lucrativos, no sentido do bem comum. 
Nesta definição, agregam-se, estatística e conceitualmente, um conjunto altamente diversificado de instituições, no qual incluem-se organizações não governamentais, fundações e institutos empresariais, associações comunitárias, entidades assistenciais e filantrópicas, assim como várias outras instituições sem fins lucrativos (COSTA;VISCONTI, 2001, p.04).

É a partir desse tipo de ideologia que surgem os termos "responsabilidade social", "voluntariado", "gestão responsável" e tantos outros que ocupam as grandes redes de comunicação, moldando a consciência da classe trabalhadora e eximindo a ordem vigente, jogando a responsabilidade no indivíduo que incorpora uma "missão", quase no sentido religioso do termo, em resolver os problemas sociais.

Foram ações que se firmaram com o Governo FHC e continuaram nos governos sequentes, quando se intensificou o movimento empresarial dentro da sociedade civil, através da criação de organizações que buscavam incentivar a ação burguesa, reunindo empresas de porte e setores diversificados a fim de criar novas estratégias de intervenção para reeducar a sociabilidade e, ainda, expandir e instigar o novo comportamento empresarial na sociedade. Foram instituídos, assim, organizações como o GIFE $^{6}$ e o Instituto Ethos, que tinham como objetivo principal organizar as ações sociais das empresas a partir do investimento privado.

Numa perspectiva crítica, o GIFE existe para disseminar o modelo de gestão emanado das experiências e sistematização da classe burguesa como referencia para ordenar de maneira eficiente e produtiva a nova sociabilidade a partir do redirecionamento do trabalho das organizações da face popular da sociedade civil educando-os para incorporar o preceito burguês da colaboração e da conciliação social (MARTINS, 2009, p.143).

Esses organismos ocuparam um papel fundamental na conscientização dos empresários sobre a importância de desenvolver ações coletivas através da "Responsabilidade Social", a fim de disseminar um trabalho educativo que proporcionasse a afirmação da nova sociabilidade do capital. O GIFE, por exemplo, pode ser considerado pioneiro, a partir de 1990, na organização da mudança de comportamento político tanto da sociedade quanto do setor empresarial, responsável por dar um novo rumo às intervenções político-sociais da burguesia, de modo que, o que eram ações fragmentadas, pontuais e filantrópicas passaram a ser dirigidas sob um novo ângulo, difundindo que o modelo empresarial deveria ultrapassar os limites de gestão da empresa e ser adotado pela sociedade civil como referência no campo social. Neste sentido, o GIFE se configura como um aparelho privado de hegemonia compactuante e disseminador dos princípios burgueses.

No governo de Fernando Henrique Cardoso, o país mergulhou no neoliberalismo de terceira via, no qual o Estado funcionaria como um importante parceiro no processo de reeducação social, conceitos como responsabilidade social corporativa ${ }^{7}$ (que derivou do Pacto Global das Nações Unidas, firmado em 1999, por iniciativa da ONU, no qual várias empresas firmaram um pacto com o objetivo de incentivar a ação tanto de pessoas quanto de empresas em diversas áreas públicas, como escolas e hospitais) ganharam espaço para se solidificar buscando impulsionar o apoio das empresas a questões de responsabilidade ambiental, por exemplo.

E, subsequentemente, nos governos de Luiz Inácio Lula da Silva, ganhando um significativo aumento na adesão por parte dos empresários à "causa social". Ou seja, as 
regras do jogo neoliberal foram mantidas, o governo tomou como objetivo "retomar o crescimento e corrigir as injustiças sociais sem alterar as realizações neoliberais herdadas do governo anterior" (MARTINS 2009, p. 222). Para tal, buscou consolidar as noções de voluntariado, fortalecer a parceria público/privado e redirecionar o papel da sociedade civil, na busca de uma ampla difusão da nova sociabilidade.

\begin{abstract}
Basicamente elas desenvolvem projetos que: incentivam o desenvolvimento do capital social em comunidades carentes; estimulam o crescimento do voluntariado; impulsionaram a implantação de "padrões de excelência em gestão" em organizações da sociedade civil, responsáveis por executar políticas sociais em diferentes áreas, procurando transformar a sociedade civil numa instancia de relações harmoniosas, de colaboração entre indivíduos e de coesão cívica identificados com o programa da Terceira Via" (MARTINS, 2009 p. 164).
\end{abstract}

Assim, as empresas desenvolvem, muitas vezes, projetos isolados em comunidades carentes, atingindo uma proporção mínima de "beneficiados", tentando resolver problemas sociais que, na verdade, forma criados em conjunto por elas mesmas. Algumas formas concretas de como empregar essa ideologia da "responsabilidade social" em ações concretas são os projetos sociais desenvolvidos pelas empresas, como, por exemplo, na cidade de Campina Grande - PB , onde, atualmente são desenvolvidas algumas ações que serão elencadas a título de exemplificação. São eles: projeto "Caravana do Bem", "Projeto Educação por Meio do Esporte", projeto "Paralapracá" e o "Criança Esperança", que não é desenvolvido na cidade, porém é um exemplo sólido de tais parcerias:

O projeto "Caravana do Bem" oferecido pela empresa $\mathrm{AeC}^{8}$, consiste na dedicação, por parte dos funcionários, de algumas horas para a realização de um curso básico proposto pela empresa de "Contadores e ledores de história", que é oferecido por uma trupe de artistas. E ainda, juntos, formam kit's literários para a doação as crianças das escolas que participam, praticando o que eles chamam de "Cidadania Cultural". Por cidadania cultural, "pleiteia o direito à comunicação e à representação da diferença cultural (MILLER, 2011)", entendimento bastante diverso do expresso por Chaú (2006), para quem esse conceito expressa uma forma de persuasão da consciência das massas, deixando o lado crítico e reflexivo do pensamento e aderindo à concepção instrumental da cultura.

O Instituto Alpargatas coordena o Projeto Educação por Meio do Esporte, programa de voluntariado no qual também são os funcionários designados para atuar. Este projeto, especificamente, atua direto na escola, oferecendo práticas esportivas num horário extraaula, apoio financeiro para aquisição de material pedagógico esportivo e na estruturação física necessária, tudo isso arrecadado por meio de doações.

O Projeto Paralapracá, proporcionado pelo Instituto C\&A, também atua diretamente na escola, e se propõe a "contribuir para a melhoria da qualidade do atendimento às crianças na educação infantil, com vistas ao seu desenvolvimento integral." (PEREIRA; AMORIM; CRISPIM, 2014, p.01). Para cumprir tal objetivo, o Instituto fornece um tipo de formação continuada para os professores, interferindo diretamente em seus métodos de trabalho pedagógico.

E, por fim, talvez a ação social mais reconhecida pela mídia, "o Criança Esperança", por meio do qual, todos os anos, milhões e milhões de pessoas doam seu dinheiro a um programa que diz não ter fim lucrativo algum, com a promessa de ajudar ao 
próximo. A Rede Globo, patrocinadora desse programa, entrega seu imposto de renda no ano seguinte com desconto de mais de 20 milhões por doação feita ao Unicef. E esse tipo de ação não é crime, porque o dinheiro é entregue ao Unicef, no entanto, não é a pessoa que doou que o entrega e sim a Rede Globo, por isso não há redução no imposto de quem doa $^{9}$.

Nessa campanha de arrecadação, há um apelo midiático emocional forte. Há um chamamento da sociedade, e esse chamamento configura-se como responsabilização social, na medida em que a mídia passa a responsabilidade de sanar as questões sociais para a população, por meio de propagandas que ressaltam a pobreza a que estão sujeitas as crianças brasileiras, e como as ações promovidas pelo Unicef, tão eficazes no combate a essas carências, somente são possíveis com a ajuda financeira da população.

Conforme se compreende, essas e outras ações não podem ser encaradas como "bondosas", mas sim, como imbuídas de interesse de classe em difundir valores, formas de pensar e comportamentos que sejam compatíveis com sua visão de mundo.

Forja-se uma cultura cívica (ainda que cínica), democrática (que incita à participação e à representação) para educar o consenso e disciplinar as massas de trabalhadores, em boa parte desprovida de direitos associados ao trabalho, através de categorias como "empoderamento", "responsabilidade empresarial", empresa cidadã", "sustentabilidade". (FONTES, 2010, apud VITULLO, 2012, p. 168).

Conceitos disseminados de maneira tão persuasiva que chega a não ser cogitada, pela sociedade, a recusa a aderir a tais ações voluntárias, que acabam virando requisito para empregabilidade. É esse aporte midiático que funciona como atrativo para novos adeptos, principalmente os consumidores que, por sua vez, contaminados com essa "lógica solidária”, movem-se como cidadãos socialmente responsáveis. E, também, os funcionários que são sensibilizados a participar voluntariamente das ações sociais promovidas pelas empresas, em muitos casos, aumentando sua jornada de trabalho em prol dessas ações (VITULLO, 20012). São ações que se configuram muito mais como assistencialistas, na medida em que não atingem uma parcela significativa da população, trazendo muito mais beneficio para a empresa do que para quem as recebe. E, diga-se de passagem, muito menos para o trabalhador que as executa.

\section{A FACE HUMANA DO CAPITAL?}

A expressão "responsabilidade social" não é um termo novo, segundo Martins (2009), ele já era citado em debates e publicações nos Estados Unidos entre os anos de 1920 e 1950, passando a ser mais recorrente a partir dos anos de 1970, porém não acarretava o cunho ideológico que atualmente carrega. Naquele momento, "[o] desafio traçado foi o de restituir os valores sociais e tornar os Estados Unidos uma nação de voluntários engajados numa causa comum" (MARTINS 2009, p. 151). O conceito mais recente implica demonstrar que as empresas são socialmente responsáveis em investir parte dos lucros na promoção do bem estar da população, devolvendo parte daquilo que arrecadam a sociedade.

No entanto, como já foi afirmado, além de difundir uma nova dimensão política de cidadania e participação ativa da sociedade civil, a ideologia da "responsabilidade social" fornece à empresa capital midiático, isto porque, segundo a revista Exame, "a responsabilidade social corporativa tem um peso de $41 \%$ nas avaliações dos consumidores 
sobre a reputação de uma empresa" (MELO, 2013). Assim, a ideia a ser propagada é promover a necessidade de compra através da mídia, das propagandas de comercialização do produto e, ao mesmo tempo, transmitir uma imagem de uma empresa socialmente preocupada com o futuro do país, por exemplo.

Desse modo, o trabalho social vira um tipo de "produto" "comercializável", que proporciona a empresa agregar a sua marca uma imagem socialmente responsável. Uma prova dessa vantagem conseguida com a "imagem solidária" é que, segundo Paoli (2002, p.396), "nos casos nos quais o empresário não opta por organizar uma entidade especifica para o trabalho social (fundações ou institutos) este é alocado nos departamentos de marketing ${ }^{10}$ da empresa".

Funciona, ainda, como um autorregulador da luta de classes, afinal é uma ideologia baseada no voluntariado, por consequência, o voluntariado é fundamentado em princípios altruístas, portanto liberto de amarrações e códigos classistas, isso significa dizer que não existe mais divisão de classe e que indivíduos encharcados desse tipo de pensamento pensam no "bem de terceiros" e, ao invés de reivindicar direitos, eles buscam fazer, realizar ações em prol desses terceiros, ou seja, funciona como um organizador da cultura (MARTINS, 2009) e da nova sociabilidade.

Neste sentido, esse tipo de ação busca fornecer ao capitalismo uma nova cara, o objetivo é "confeccionar uma nova e atraente roupagem sem, contudo mudar o manequim" (VITULLO, 2012, p.16). Podemos, de maneira geral, descrever assim a tentativa de transformar o capitalismo em um capitalismo mais humano, maquia-se o discurso, trocamse os termos, trabalhador passa a ser chamado de colaborador, capitalista de empreendedor, cidadão de consumidor e assim sucessivamente afirmando que as posições sociais não se modificam, há somente a agregação de uma responsabilidade para com a sociedade, na qual todos têm seu papel definido.

São iniciativas que visam transformar o trabalhador em um tipo de cidadão voluntário, seja por meio do convencimento ou da coerção, em um colaborador da empresa, na busca da construção da "empresa-cidadã". Com isso, o voluntariado, o engajamento dentro da ideologia da responsabilidade social tornou-se também critério de empregabilidade (MARTINS, 2009).

No entanto, a questão vai muito mais além do que somente o aporte midiático que tais empresas acabam por agregar a sua imagem, ou outro ponto citado: a questão vinculase à manutenção da ordem social vigente, à medida que busca promover a população a ocupar um papel que deveria ser do Estado,

Objetiva-se, então, fomentar o discurso valorizador de uma solidariedade privada que ocupe o espaço deixado por um Estado incessantemente desregulamentado em seus vínculos com o trabalho e, de preferência, escasso de organizações classistas. Sobra, portanto, a ideologia dominante na qual atitudes e palavras veem o que é humano como sendo apenas uma mistura de mercadoria e de carência afetiva individualista. Segundo essa ótica, os problemas daí advindos devem ser resolvidos por doações caritativas e empreendedorismo comercial que, por sua vez atuariam como um novo campo de relações sociais, pretensamente neutro (VITULLO, 2012, p. 30).

Assim, o objetivo está concentrado em, cada vez mais, homogeneizar a classe trabalhadora, em garantir que cada um se integre a causa que a empresa apoia, bem como 
em inculcar que cada um é responsável por nivelar as discrepâncias sociais existentes na busca da construção de um mundo mais equilibrado, cria-se o termo de "família empresarial", visando à integração entre trabalhadores e patrões destruindo aparentemente qualquer forma de dominação, afinal, tanto um quanto o outro estariam trabalhando em prol de do mesmo ideal.

A ideologia da responsabilidade social permite que empresas distintas e de diferentes lugares atuem com um mesmo objetivo, "nessa lógica, o agir de forma responsável significa contribuir para a edificação da estabilidade política, social e ambiental do país e do mundo, assegurando assim, a coesão cívica de todos os indivíduos em favor do bem comum, como defende a terceira via” (MARTINS 2009, p.175) suscitando o voluntariado, a parceria público/privado.

Tudo isso funcionaria como um regulador, um harmonizador social de conflitos que não interessassem a classe empresarial. E mais, segundo Martins (2009), significa que a empresa deve atuar como um aparelho privado de hegemonia, para que sejam asseguradas as mudanças de comportamento da massa trabalhadora dentro e fora do espaço de produção, a fim de garantir e legitimar as relações tanto sociais quanto de poder que já vigoram.

\section{Referências}

COSTA, Cláudia Soares; VISCONTI, Gabriel Rangel. Terceiro Setor e Desenvolvimento Social. Gerência de Estudos Setoriais. Relato Setorial, n.3, jul. 2001. Disponível em: $<$ http://www.bndes.gov.br/SiteBNDES/export/sites/default/bndes_pt/Galerias/Arquivos/conecimento/rel ato/tsetor.pdf $>$. Acesso em: 09 fev. 2014

KOTLER, P. Administração de marketing:análise, planejamento, implementação e

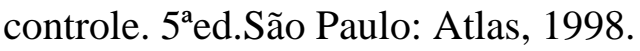

MARTINS, André Silva. A direita para o social: educação da sociabilidade no

Brasil contemporâneo. André Silva Martins. - Juiz de Fora: UFJF, 2009.

MARTINS, André Silva. Classe empresarial e o plano nacional de educação: uma analise sobre um processo ainda em curso. Inc.: Novo Plano Nacional de Educação (PNE): debates e tensões / Organizadoras Andréia Ferreira da Silva, Melânia Mendonça Rodrigues. - 1. Ed - Campina Grande: EDUFCG, 2013.

MELO, Luísa. As 10 empresas com mais responsabilidade social no mundo. Revista EXAME. São Paulo, out. 2013. Disponível em: $<$ http://exame.abril.com.br/negocios/album-de-fotos/as-10-empresas-com-maisresponsabilidade-social-no-mundo>. Acesso em: 15 mar. 2014

MILLER, Toby. Cidadania Cultural. MATRIZes, São Paulo, Brasil, v. 4, n. 2, jan./jun. 2011. Disponível em: < http://www.matrizes.usp.br/index.php/matrizes/article/view/58/86>. Acesso em: 05 fev. 2014 
PAOLI, Maria Célia. Empresas e responsabilidade social: os enredamentos da cidadania no Brasil. Inc. Democratizar a democracia: os caminhos da democracia participativa / Boa ventura de Sousa Santos, organizador. - Rio de Janeiro: Civilização brasileira, 2002.

PEREIRA, Sheila; AMORIM, Fernanda; CRISPIM, William. Instituto C\&A promove Educação Infantil com o projeto Paralápracá. São Paulo, set. 2014 Disponível em: < http://www.institutocea.org.br/noticias/detalhe-release.aspx?id=221>. Acesso em: $22 \mathrm{abr}$. 2014

SÃO PAULO ALPARGATAS S.A. Instituto Alpargatas. Relatório anual/ Relatório Social. São Paulo, 2005. Disponível em:< http://ri.alpargatas.com.br/arquivos/informacoes_financeiras/relatorios_Anuais/2005/16

_03_2006_Rel_Anual_2005.pdf >. Acesso em: 13 abr. 2014

VITULLO, Gabriel Eduardo. A ideologia do "Terceiro Setor”: ensaios críticos/

organizador Gabriel Eduardo Vitullo. - Natal, RN: EDUFRN, 2012. 226 p

\footnotetext{
${ }^{1}$ Graduanda do curso de Licenciatura Plena em Pedagogia pela Universidade Federal de Campina Grande UFCG. Bolsistas do Programa de Educação Tutorial (PET). E-mail: alined.leal@ hotmail.com.

${ }^{2}$ Professora Associada da UFCG;Tutora do Grupo PET/Pedagogia. E-mail: melania.r@uol.com.br.

${ }^{3}$ Desenvolvida como atividade da pesquisadora como integrante do Programa de Educação Tutorial (PET), Grupo do Curso de Pedagogia da UFCG, sob orientação da tutora do Grupo, professora Dra. Melânia Rodrigues.

${ }^{4}$ Grifo do autor

5 A tarefa de inculcamento de uma linguagem nova precisa de um martelar constante para que se torne comum e banalizada. Ao ponto de se escrever, dizer e gestualizar num átimo que os valores sociais antes expressos,agora denotam outros.Ou seja,uma palavra no passado agregadora de um significado crítico assume outro politicamente mais suave ao poder dominante.(VITULLO,2012,p. 13)

${ }^{6}$ Grupo de Institutos, Fundações e Empresas.

7 "Registra-seque as organizações empresariais com sede no exterior, principalmente nos Estados Unidos, substituem o termo "responsabilidade Social empresarial"(ou responsabilidade social) por "Responsabilidade corporativa", sendo que esta forma também é empregada no país com certa frequência"(MARTINS,2009,p.149).
}

8 A AeC é uma empresa brasileira de serviços outsourcing nas áreas de Contact Center, Consultoria, Software e Gestão em Saúde. (http://www.aec.com.br/sobre_a_AeC/Pages/SobreaAeC.aspx)

9 A Globo deve algumas explicações sobre o criança esperança,2011 apud VITULLO,2012,p.198

10 Entendendo se aqui,a função do setor de marketing como "um processo social e gerencial pelo qual indivíduos e grupos obtêm o que necessitam e desejam através da criação,oferta e troca de produtos de valor com outros"(KOTLER. 1998 p. 27).

Recebido: jun2015 Aprovado: jul/2015 